\title{
Struktur Komunitas Makro Alga di Perairan Desa Mata Sulawesi Tenggara
}

\author{
${ }^{1 *}$ Ira \\ ${ }^{1 *}$ Fakultas Perikanan dan Ilmu Kelautan Universitas Halu Oleo \\ Email: irafpikunhalu@gmail.com
}

Diterima: 26 Februari 2018 Publish: 28 Juni 2018

Abstrak

Makroalga termasuk salah satu sumberdaya hayati laut yang banyak terdapat di perairan Indonesia. Makroalga memiliki potensi besar untuk dikembangkan, karena memiliki peranan penting baik dari segi ekologis maupun ekonomis. Tujuan penelitian adalah untuk mendapatkan informasi mengenai struktur komunitas makroalga yang ada di perairan Desa Mata Kecamatan Kambowa Kabupaten Buton Utara. Penelitian ini dilaksanakan pada bulan Desember 2014-Januari 2015. Metode yang digunakan adalah metode kuadran ukuran 1x 1 $\mathrm{m}^{2}$ yang diletakkan pada garis transek sepanjang $100 \mathrm{~m}$ dengan interval $10 \mathrm{~m}$. Makroalga yang ditemukan 17 spesies yang terdiri atas Kelas Chlorophyta berjumlah 7 jenis, kelas Phaeophyta 3 jenis dan kelas Rhodophyta 7 jenis. Komposisi jenis makroalga didominasi oleh kelas Chlorophyta (39\%), Kelas Phaeophyta (37\%) dan kelas Rhodophyta (24\%). Indeks keanekaragaman makroalga sekitar 2.058 dikategorikan sedang, indeks keseragaman sekitar 0.726 dikategorikan tinggi dan indeks dominansi 0.198 dikategorikan rendah.

Kata Kunci: Makroalga, komunitas dan keanekaragam

\begin{abstract}
Macroalgae is one of the marine biological resources that are found in Indonesian waters. Macroalgae has great potential to develop, because it has an important role both in terms of ecological and economical. The study aimed to obtain information on the community structure of macroalgae in Mata village water, Kambowa districts, north buton district south east Sulawesi. The study was conducted in December 2014-January 2015. The method used in study is a sampling squares transect $1 \times 1 \mathrm{~m}^{2}$ and other is $10 \mathrm{~m}$ distance and $100 \mathrm{~m}$ lenght. The observation was found that the number of macroalgae spesies consisted of 17 species consisting of chlorophyta class 7 species, phaeophyta class 3species dan rhodophyta class 7 species. The composition was dominated by chlorophyta class (39\%), phaeophyta class $(37 \%)$ and rhodophyta class $(24 \%)$. Density of macroalgae with a value of 2.058 which is the category was based on the index of diversity, uniformity value amounted to 0.726 with a high category indexes based on uniformity while for dominance with value amounted to 0.198 and low dominance categorized based on the index of dominance.
\end{abstract}

Key words: Macroalgae, comunity and biodiversity 


\section{Pendahuluan}

Makroalga merupakan salah satu organisme tingkat rendah yang keberadaannya sangat melimpah, termasuk di Indonesia, yang menjadi habitat bagi 88 jenis alga dari seluruh alga yang ada di dunia (Tomascik et al., 1997). Sebagian besar makroalga di Indonesia memiliki nilai ekonomis yang tinggi dan sebagian digunakan langsung oleh masyarakat pesisir. Secara umum, makroalga kaya akan vitamin A, E, C, dan niacin (Kilinc et al. 2013). Saat ini, konsumsi manusia terhadap alga hijau sekitar 5\%, alga cokelat 66,5\%, dan alga merah $33 \%$. Konsumsi alga yang tinggi terdapat di Asia, terutama Jepang, Cina, dan Korea (Dawes, 1998).

Pemanfaatan makroalga kemudian berkembang untuk kebutuhan bahan baku industri makanan, kosmetik, farmasi dan kedokteran. Menurut Mishra et al. (1993), makroalga merupakan bahan baku untuk produksi industri agar-agar, algin, dan karagenan. Selain itu Jung et al. (2012) telah membuktikan adanya potensial makroalga sebagai bahan baku untuk biorefinery dengan memperkenalkan klasifikasi taksonomi, habitat lingkungan, dan kapasitas karbon cadangan. Menurut Dr Fabien Deswarte, Biorefinery merupakan bidang terbarukan mengubah bahan baku ke biomaterial yang berguna, biokimia dan bahan bakar bio dalam satu fasilitas terpadu.

Ditinjau dari segi ekologis, makroalga berfungsi sebagai sumber makanan bagi hewan laut (Duxbury dan Duxbury, 1989), serta memegang peranan penting dalam produktivitas primer di laut (Dawes, 1998). Diperkirakan bahwa produksi bersih makroalga yang memasuki jaring makanan melalui pemangsaan (grazing) hanya 10\%, sedangkan sisanya sebesar 90\% masuk melalui rantai bentuk detritus atau bahan organik terlarut (Nybakken, 1992).

Mata merupakan salah satu Desa yang berada di Kecamatan Kambowa Kabupaten Buton Utara. Desa ini mempunyai perairan laut yang memiliki topografi yang datar sampai landai dengan tingkat kemiringan lereng yang tidak terlalu bervariasi. Di pinggir pantainya dikelilingi oleh tumbuhan mangrove, juga terdapat makroalga yang tersebar pada salah satu habitat yang ada di perairan tersebut yaitu bersubstrat pasir, pecahanpecahan batu dan rataan terumbu. Belum teridentifikasi jenis dan masih belum adanya kajian khusus mengenai makroalga, sehingga penelitian untuk mengetahui struktur komunitas makroalga di perairan Desa Mata tersebut perlu dilakukan. 


\section{Bahan dan Metode}

\section{Waktu dan Tempat}

Pengambilan sampel makroalga di perairan Desa Mata yang terletak diantara $5^{\circ} 06^{\prime} 46^{\prime \prime} \quad S$ dan $122^{\circ} 58^{\prime} 26^{\prime \prime}$ E di
Kecamatan Kambowa Kabupaten Buton Utara Sulawesi Tenggara. Identifikasi sampel makroalga dilakukan di Laboratorium Fakultas Perikanan dan Ilmu Kelautan Universitas Halu Oleo Kendari. Penelitian berlangsung selama bulan Desember 2014-Januari 2015.

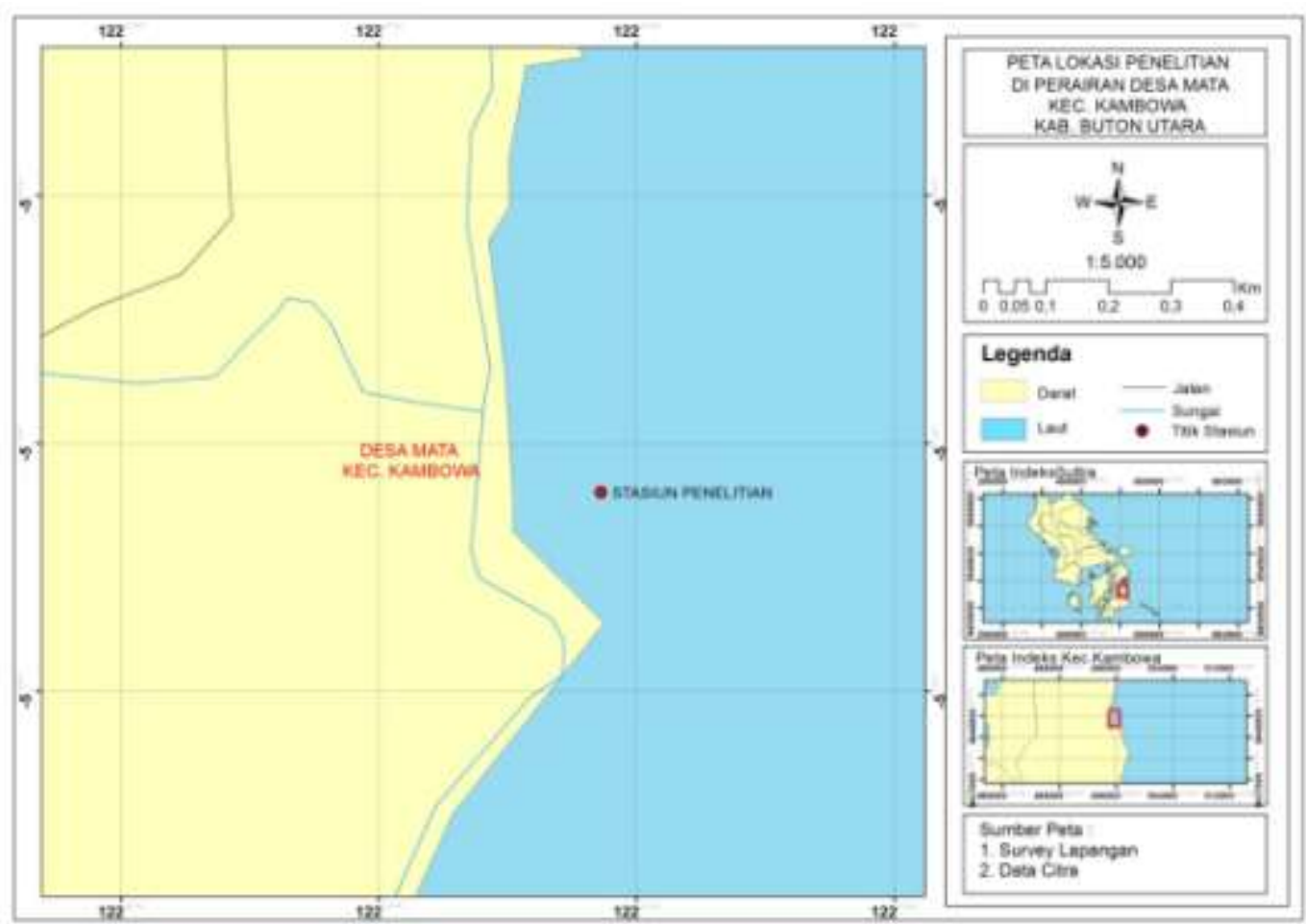

Gambar 1. Lokasi penelitian di perairan Desa Mata

\section{Pengambilan Sampel}

Pengambilan data makroalga mengacu pada metode English (1997) yang sudah dimodifikasi untuk ukuran kuadran dan interval jarak. Pengambilan sampel dilakukan dengan membentangkan transek garis tegak lurus garis pantai kearah laut yang memotong komunitas alga sepanjang $100 \mathrm{~m}$. Masing-masing transek garis diletakkan transek kuadran (1 x $\left.1 \mathrm{~m}^{2}\right)$ dengan interval $10 \mathrm{~m}$.
Pengambilan sampel dilakukan saat air laut surut.

Makroalga yang ditemukan dalam kuadran dibersihkan dari substratnya, kemudian didokumentasikan dan dimasukkan ke dalam kantong plastik yang telah diberi label. Selanjutnya dibawa ke laboratorium untuk diidentifikasi. Identifikasi makroalga menggunakan panduan Atmadja et al (1996) dan www.algabase.org. 
Pengambilan data makroalga dilakukan bersamaan dengan pengukuran parameter lingkungan. Pengukuran parameter lingkungan meliputi parameter suhu (termometer), $\mathrm{pH}$ ( $\mathrm{pH}$ indikator), kecerahan (sechidisk), kedalaman perairan (patok berskala), dan kecepatan arus (floating dredge).

\section{Analisis Data}

Data yang telah dikumpulkan dianalisis menggunakan analisis statistik deskriptif. Analisis statistik deskriptif adalah analisis yang menjelaskan atau mendeskripsikan hasil penelitian.

1. Kepadatan Jenis

Kepadatan yaitu jumlah total individu dalam suatu unit yang diukur. Kepadatan makroalga dihitung dengan menggunakan rumus Brower et al (1998).

$\mathrm{Di}=\frac{n i}{A}$

Keterangan:

Di =kepadatan spesies untuk spesies ke-i (ind $/ \mathrm{m}^{2}$ )

ni $=$ jumlah total individu spesies ke-i(ind)

$\mathrm{A}=$ luas total daerah yang disampling (m)

2. Frekuensi Jenis

Frekuensi jenis yaitu peluang suatu jenis ditemukan dalam titik sampel yang diamati. Frekuensi jenis makroalga dihitung dengan rumus (Odum, 1993).

$\mathrm{Fi}=\frac{\mathrm{Pi}}{\sum \mathrm{P}}$
Keterangan:

$\mathrm{Fi}=$ frekuensi spesies ke-i

$\mathrm{Pi}=$ jumlah petak sampel yang ditemukan jenis ke-i

$\Sigma \mathrm{P}=$ jumlah total petak sampel yang diamati

3. Keanekaragaman Jenis

Keanekaragaman jenis merupakan suatu karakteristik tingkatan komunitas berdasarkan organisasi komunitasnya. Keanekaragaman jenis makroalga dihitung dengan menggunakan rumus indeks Shannon-Wiener (Odum, 1993).

$\mathrm{H}^{\prime}=\sum_{k=0}^{n} \mathrm{Pi} \ln \mathrm{Pi}$

Keterangan:

$\mathrm{H}^{\prime}=$ indeks keanekaragaman jenis

$\mathrm{ni}=$ jumlah individu jenis ke $\mathrm{i}$

$\mathrm{N}=$ jumlah total individu

Semakin besar nilai indeks keanekaragaman maka semakin tinggi keanekaragaman jenisnya, berarti komunitas biota di perairan tersebut makin beragam dan tidak didominansi oleh satu atau dua jenis.

4. Keseragaman

Indeks

keseragaman

menggambarkan keseimbangan penyebaran spesies dalam suatu komunitas. Indeks ini dihitung dengan menggunakan rumus Evennes (Odum, 1993). 
$E=\frac{\mathrm{H}^{\prime}}{\mathrm{H} \max }$

Keterangan:

$\mathrm{E}^{\prime}=$ indeks keseragaman

$\mathrm{H}^{\prime}=$ indeks keanekaragaman

$\mathrm{H} \max =$ keanekaragaman spesies maksimum $(\ln S)$

Semakin kecil nilai indeks keseragaman jenis menunjukkan bahwa jumlah jenis antar spesies tidak menyebar merata, dan sebaliknya semakin besar nilai indeks keseragaman, berarti jumlah antar spesies semakin menyebar merata.

5. Dominansi

Indeks dominansi dihitung dengan menggunakan rumus indeks Simpson (C). Persamaan indeks dominansi simpson digunakan untuk mengetahui spesiesspesies tertentu yang mendominasi komunitas (Odum, 1993).

$C=\sum\left(\frac{n i}{N}\right)^{2}$

Keterangan:

$\mathrm{C}=$ indeks dominansi

$\mathrm{ni}=$ jumlah individu jenis ke $\mathrm{i}$

$\mathrm{N}=$ jumlah total individu

Nilai indeks dominansi mempunyai kisaran antara 0-1. Indeks 1 menunjukkan dominansi oleh satu jenis spesies sangat tinggi. Semakin mendekati nilai 1 berarti semakin tinggi tingkat dominansi oleh spesies tertentu.

\section{Hasil dan Pembahasan}

Penelitian makroalga di perairan Desa Mata menemukan 17 jenis yang berasal dari tiga kelas. Kelas Chlorophyta berjumlah 7 jenis, kelas Phaeophyta 3 jenis dan kelas Rhodophyta 7 jenis. Komposisi jenis kelas Chlorophyta sebesar 39\%, kelas Phaeophyta dan Rhodophyta masingmasing sebesar $37 \%$ dan $24 \%$. Tingginya kelas Chlorophyta yang ditemukan disebabkan karena kelas Chlorophyta sering ditemukan tumbuh tersebar di perairan pantai sehingga lebih banyak memperoleh intensitas cahaya matahari untuk proses fotosintesis. Sebagaimana pernyataan Odum (1993), alga kelas Chlorophyta tersebar di perairan pantai, lebih ke tengah kelas Phaeophyta dan lebih dalam lagi kelas Rhodophyta. Kelas Chlorophyta memiliki pigmen dominan hijau, dimana pigmen tersebut berasal dari klorofil yang dikandung makroalga di air laut. Komposisi jenis masing-masing kelas makroalga dapat dilihat pada Gambar 2. 


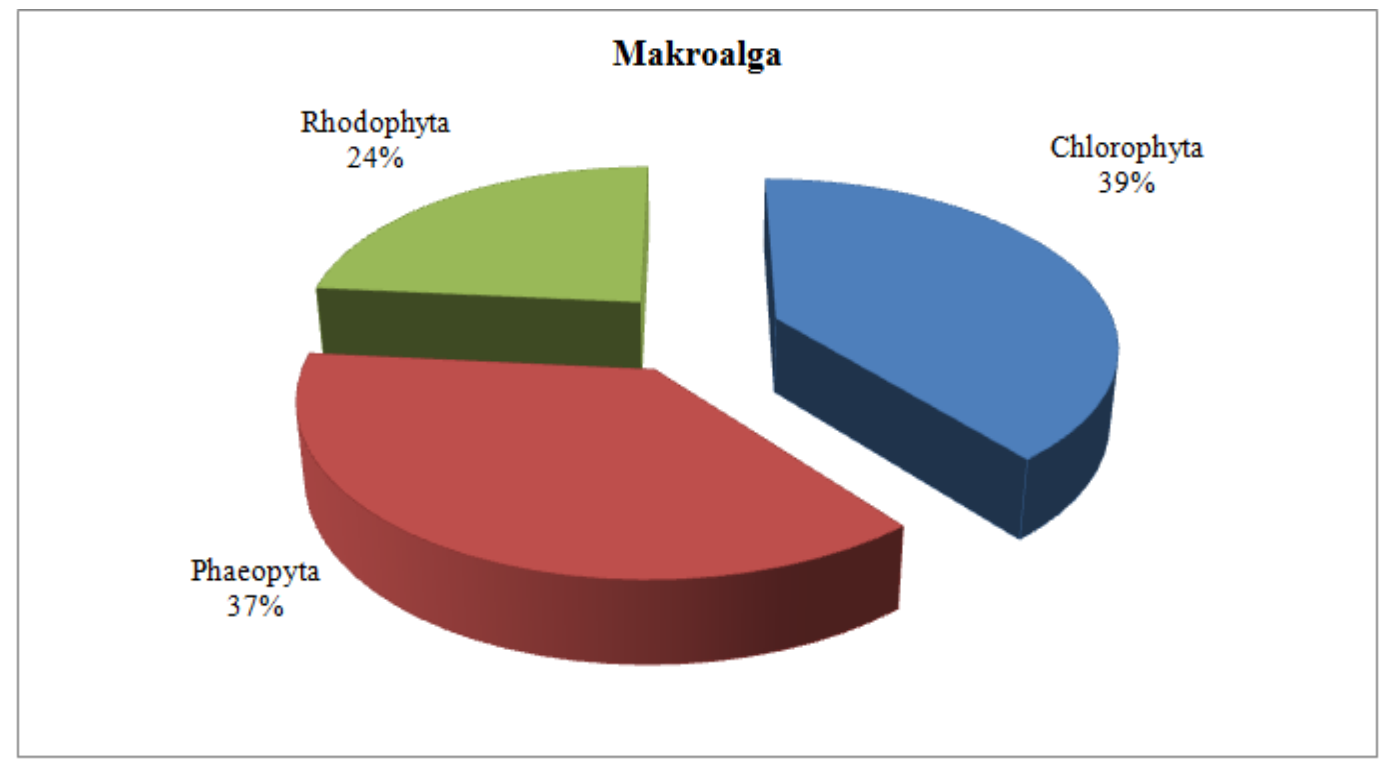

Gambar 2. Komposisi jenis makroalga di perairan Desa Mata

Total kepadatan makroalga sebesar $21.36 \mathrm{ind} / \mathrm{m}^{2}$. Makroalga yang memiliki kepadatan tertinggi terdapat pada kelas Phaeophyta yaitu Padina australis sebesar $7.40 \mathrm{ind} / \mathrm{m}^{2}$, disusul kelas Chlorophyta jenis Halimeda macroloba dan kelas Rhodophyta jenis Acanthophora spicifera masing-masing sebesar $4.98 \mathrm{ind} / \mathrm{m}^{2}$ dan $2.60 \mathrm{ind} / \mathrm{m}^{2}$. Total frekuensi jenis makroalga sebesar 2.82, dimana jenis
Padina australis paling sering ditemukan dengan frekuensi tertinggi yaitu $20 \%$, disusul jenis Acanthophora spicifera sebesar $14 \%$ dan Halimeda macroloba sebesar 13\%. Kepadatan makroalga di perairan Desa Mata dapat dilihat pada Gambar 3 dan frekuensi makroalga di perairan Desa Mata Kecamatan Kambowa dapat dilihat di Gambar 4.

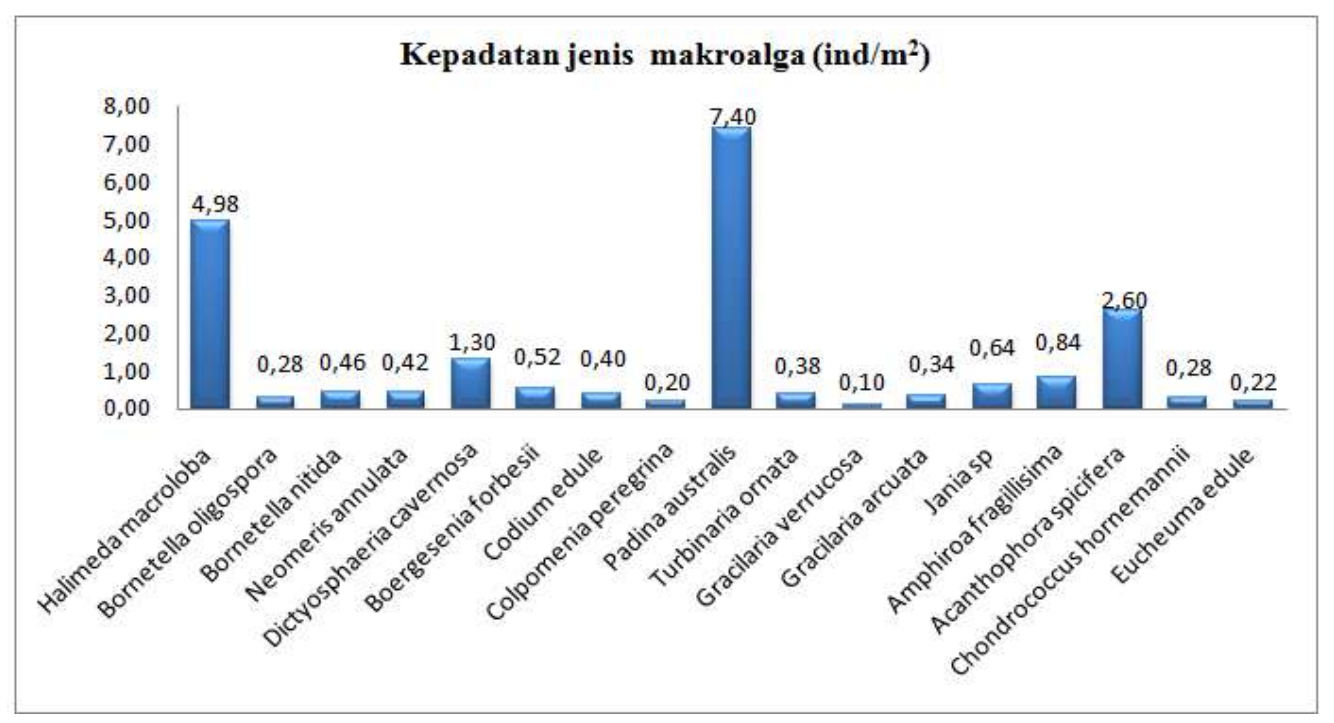

Gambar 3. Kepadatan makroalga di perairan Desa Mata 
Perbedaan kepadatan makroalga dipengaruhi oleh faktor kondisi lingkungan yang mendukung kemampuan adaptasi masing-masing spesies. Kepadatan suatu organisme ditentukan oleh kemampuan menyesuaikan diri dengan lingkungan tempat organisme itu hidup. Menurut McNaughton dan Wolf (1990), perbedaan kepadatan spesies makroalga dipengaruhi oleh beberapa faktor yaitu daya reproduksi yang tinggi, kemampuan adaptasi yang berkembang, daya tahan yang lemah terhadap habitat, adanya predator dan penyakit.

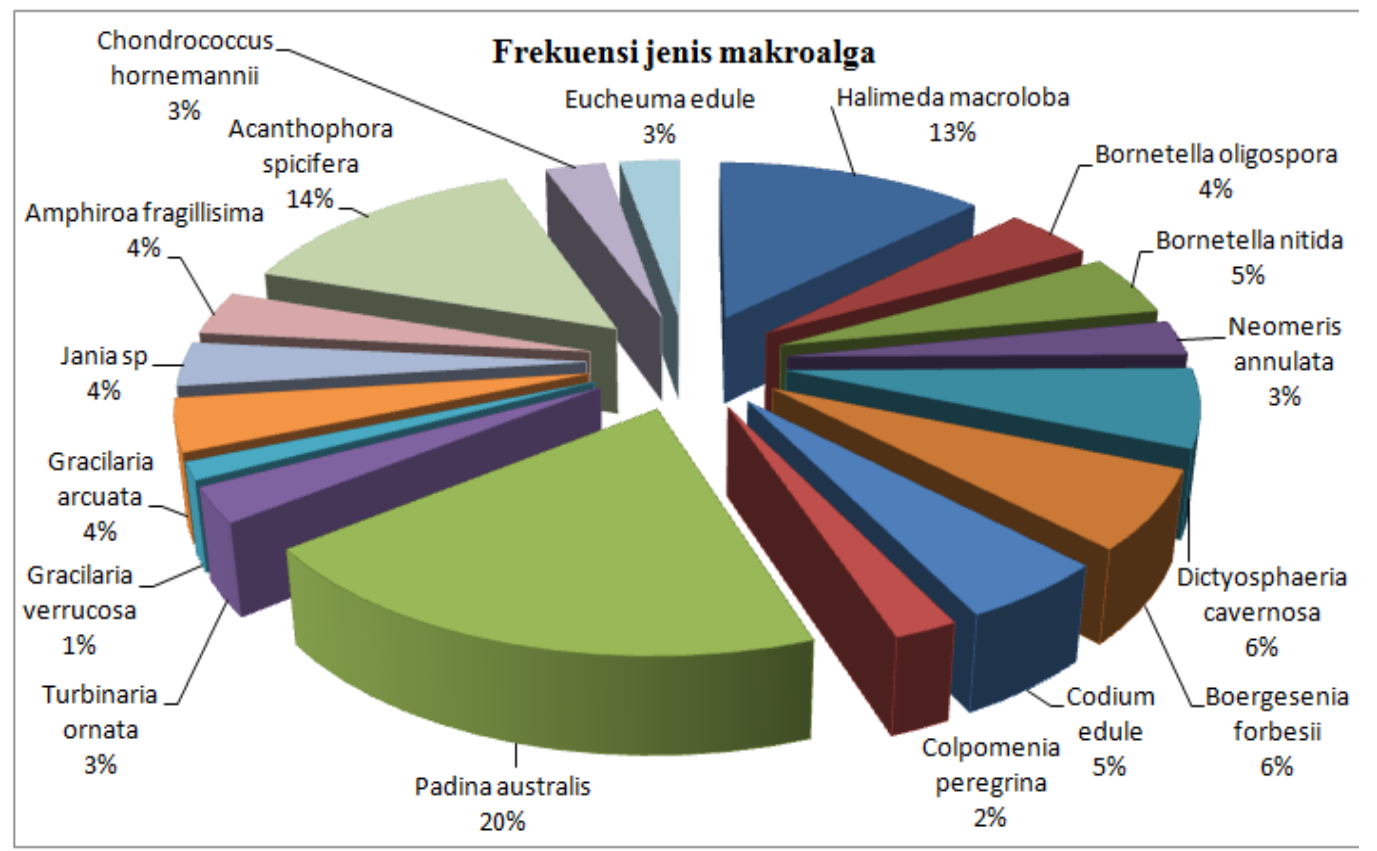

Gambar 4. Frekuensi makroalga di perairan Desa Mata

Jenis Padina australis memiliki kepadatan dan frekuensi kehadiran tertinggi dibandingkan jenis makroalga yang lain yaitu sebesar $7.40 \mathrm{ind} / \mathrm{m}^{2}$ dengan frekuensi 20\% . Di perairan Desa Mata, jenis ini ditemukan pada daerah pasir, pecahan-pecahan batu dan rataan terumbu. Ini menunjukkan bahwa Padina australis dapat tumbuh pada berbagai substrat karena memiliki kemampuan adaptasi yang cukup tinggi. Menurut Juneidi (2004) dan Pramesti (2009), Padina australis tumbuh menempel pada batu di daerah rataan terumbu karang. Sedangkan menurut Kadi dan Atmadja (1988), habitat padina tumbuh menempel pada batu di daerah terumbu baik ditempat tempat yang terkena hempasan ombak langsung maupun terlindungi. Selain itu, Padina juga dapat mentolerir keadaan kering yang lama dimana pada jenis yang lain kurang mampu untuk hidup. Padina juga merupakan jenis dengan tingkat pertumbuhan yang sangat cepat dengan kondisi lingkungan yang mendukung. 
Jenis makroalga yang memiliki kepadatan tertinggi kedua adalah Halimeda macroloba yaitu $4.98 \mathrm{ind} / \mathrm{m}^{2}$ dengan fekuensi kehadiran 13\%. Jenis ini ditemukan melekat pada pecahan-pecahan batu dan rataan terumbu di perairan Desa Mata. Holdfast berbentuk cakram pada substrat yang keras. Menurut Morthon (1990), jenis Halimeda merupakan alga hijau tropis yang paling luas distribusinya. Keberadaannya banyak dijumpai di paparan terumbu karang dengan kedalaman kurang $2 \mathrm{~m}$, pertumbuhan tahan terhadap kekeringan yang bersifat sementara waktu (Kadi, 1988). Selanjutnya Atmadja et al (1996), Halimeda mempunyai toleransi yang luas terhadap lingkungan, dimana dapat terekspos selama satu hari dan dapat tumbuh pada berbagai substrat.

Jenis Acanthophora spicifera memiliki kepadatan tertinggi setelah Halimeda macroloba yakni $2.60 \mathrm{ind} / \mathrm{m}^{2}$, namun memiliki frekuensi lebih tinggi dari Halimeda macroloba yakni 14\%. Ini menunjukkan bahwa Acanthophora spicifera merupakan salah satu jenis dari kelas Rhodophyta yang memiliki penyebaran yang luas. Seperti pernyataan Kilar dan McLachlan (1986), Acanthophora spicifera adalah alga Rhodophyta dengan distribusi luas di seluruh daerah tropis dan subtropis. Ditambahkan Manoa (2001),
Acanthophora secara luas didistribusikan ke seluruh daerah tropis dan sub tropis di zona pasang surut dan subtidal. Jenis Acanthophora spicifera ditemukan pada pecahan-pecahan batu dan rataan terumbu di perairan Desa Mata. Menurut Joikel dan Morrissey (1986), Acanthophora spicifera adalah salah satu spesies ganggang merah yang paling berlimpah yang ditemukan di terumbu flat.

Jenis makroalga yang memiliki kepadatan dan frekuensi terendah adalah Gracillaria verrucosa dan Colpomenia peregrina masing masing sebesar 0.10 $\mathrm{ind} / \mathrm{m}^{2}$ dan $0.20 \mathrm{ind} / \mathrm{m}^{2}$ untuk kepadatan sedangkan frekuensi jenisnya yakni masing-masing sebesar $1 \%$ dan $2 \%$. Jenis Gracillaria verrucosa dan Colpomenia peregrina memiliki sebaran yang rendah dan ditemukan hanya pada jenis substrat tertentu. Di perairan Desa Mata, jenis Gracillaria verrucosa dan Colpomenia peregrina ditemukan hanya di rataan terumbu. Selain itu jenis Gracillaria verrucosa dan Colpomenia peregrina ditemukan pada daerah pasang surut dan sering terdampar ke pantai karena tidak kuat menempel pada substrat sehingga mudah terbawah oleh ombak. Menurut Boo et al (2011), genus Colpomenia adalah alga coklat ditemukan di daerah beriklim sedang dan perairan tropis di seluruh dunia. Tumbuh melekat pada substrat berkarang, berbatu, berpasir dan di 
daerah sisi luar rataan terumbu karang yang umumnya selalu terendam air laut dan terkena ombak langsung.

Makroalga di perairan Desa Mata tumbuh dengan baik karena didukung oleh kualitas perairan yang memenuhi untuk pertumbuhannya, kecuali kecepatan arusnya termasuk kategori lambat dan tenang. Kecepatan arus yang terukur di perairan Desa Mata yaitu 0,040-0,063 $\mathrm{m} / \mathrm{dtk}$. Nilai tersebut termasuk tenang dan tidak memenuhi pertumbuhan makroalga. Perairan yang agak tenang justru tidak baik bagi habitat makroalga, karena akan menyebabkan terjadinya akumulasi endapan lumpur dan epifit yang melekat sehingga menghambat pertumbuhan makroalga. Pergerakan air yang baik untuk pertumbuhan makroalga adalah 0.2-0.5 m/dtk (Atmadja et al., 1996). Sedangkan menurut Widyastuti (2008), mengemukakan bahwa kisaran nilai kecepatan arus yang baik untuk pertumbuhan makroalga $0,10-0,50 \mathrm{~m} / \mathrm{dtk}$.

Parameter lingkungan seperti parameter suhu, $\mathrm{pH}$, kedalaman dan kecerahan perairan memenuhi pertumbuhan makroalga. Suhu perairan yang terukur di perairan Desa Mata yaitu $30{ }^{\circ} \mathrm{C}$. Menurut Luning (1990), bahwa suhu optimal untuk pertumbuhan makroalga di daerah tropis berkisar antara $15^{\circ} \mathrm{C}-30^{\circ} \mathrm{C}$. Ambang batas suhu untuk pertumbuhan alga hijau, coklat dan merah adalah $34,5^{\circ} \mathrm{C}-37^{\circ} \mathrm{C}$ (Hutagalung, 1988). $\mathrm{pH}$ perairannya sekitar 8. Menurut Indriana dan Sumiarsih (1992) kisaran pH perairan yang normal bagi pertumbuhan makroalga adalah 7,3-8,2.

Kedalaman perairan sekitar 1-167 $\mathrm{cm}$. Makroalga masih dapat hidup, karena sinar matahari masih dapat menembus sampai dasar perairan sehingga makroalga dapat melakukan fotosintesis. Menurut Kadi (1988) makroalga dapat tumbuh di kedalaman perairan 1-200 m tetapi kehadiran jenisnya banyak dijumpai di paparan terumbu karang pada kedalaman 1-5 m. Keberadaan suatu jenis makroalga pada kedalaman tertentu dipengaruhi oleh penetrasi cahaya matahari. Nilai kecerahan air di perairan Desa Mata adalah mencapai $100 \%$.

Indeks keanekaragaman makroalga di perairan Desa Mata sebesar 2.058. Nilai keanekaragaman tersebut termasuk kategori sedang berdasarkan kriteria indeks keanekaragaman Shannon-Weinner yang dikemukakan oleh Odum (1993), yang menyebutkan bahwa nilai $1<\mathrm{H}^{\prime}<3$, artinya keanekaragaman jenis sedang. Tinggi rendahnya keanekaragaman spesies di suatu perairan sangat dipengaruhi oleh jumlah spesies itu sendiri. Semakin tinggi jumlah spesies maka keanekaragamannya akan semakin tinggi. Jumlah spesies yang ditemukan di perairan Desa Mata berjumlah 17 spesies. Penelitian Ayhuan et 
al., (2017) menemukan keanekaragaman makroalga mendekati kategori tinggi di pesisir pulau Mansiman dan Lemon (Manokwari) yakni 2.80 dan 2.83, dengan jumlah jenis makroalga 21. Menurut Nirwan et al., (2013) bahwa semakin sedikit jumlah jenis dan jumlah individu setiap jenis suatu organisme maka nilai indeks keanekaragaman semakin kecil. Indeks keanekaragaman, keseragaman dan dominansi makroalga di perairan Desa Mata dapat dilihat pada Gambar 5.

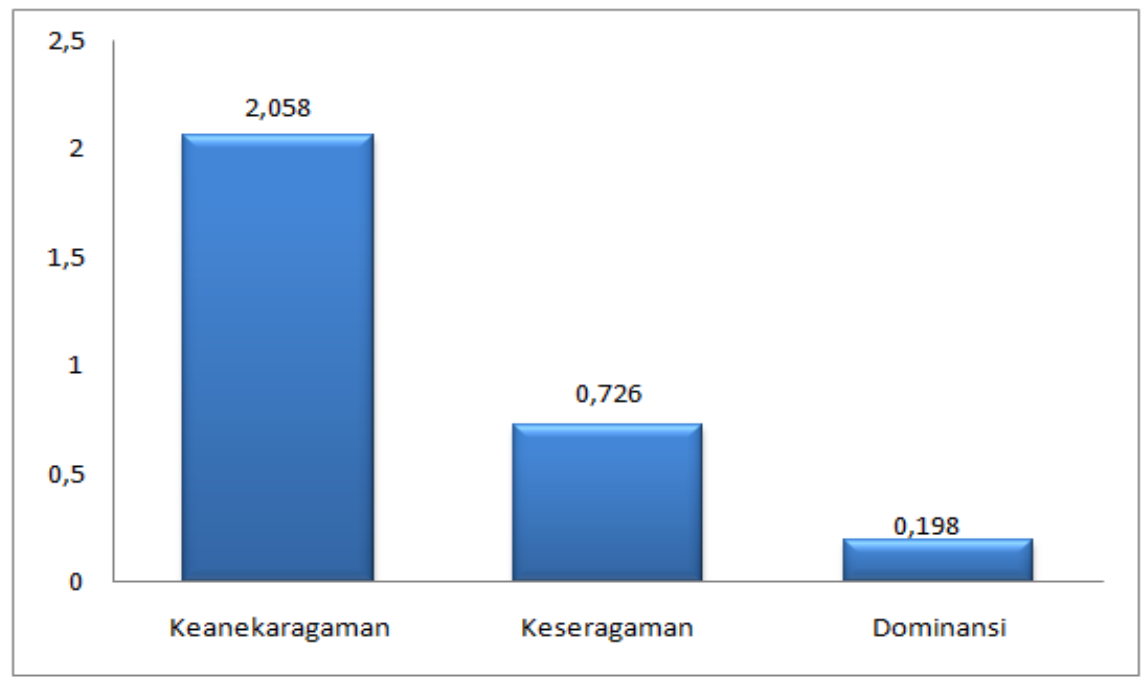

Gambar 5.Indeks keanekaragaman, keseragaman dan dominansi makroalga di perairan Desa Mata

Indeks keseragaman digunakan untuk menggambarkan keadaan jumlah spesies atau genus yang mendominasi atau bervariasi. Keseragaman merupakan keseimbangan dari komposisi individu tiap komunitas. Komunitas yang dibentuk oleh beberapa spesies yang melimpah maka keseragaman spesies dikatakan rendah (Odum, 1993). Indeks keseragaman makroalga di perairan Desa Mata sebesar 0.726. Nilai keseragaman tersebut termasuk kategori tinggi. Sebagaimana menurut nilai indeks keseragaman lebih dari 0.6 ( $\mathrm{E}>0.6)$ menunjukkan keseragaman tinggi dan dalam kondisi stabil. Menurut Palallo (2013), keseragaman yang tinggi menunjukkan bahwa jumlah antara makroalga yang ditemukan tidak berbeda jauh (merata).

Indeks dominansi adalah suatu pernyataan atau penggambaran secara matematik yang melukiskan jumlah komunitas pada suatu daerah tertentu. Apabila nilai suatu indeks dominansi mendekati satu maka ada satu spesies yang dominan dan apabila nilainya mendekati nol maka tidak ada spesies yang dominan (Odum, 1993). Indeks dominansi jenis makroalga yang ditemukan di perairan Desa Mata sebesar 0.198. Berdasarkan indeks dominansi simpson nilai indeks dominansi tersebut termasuk kategori 
rendah. Ini menunjukkan tidak ada makroalga yang dominan ditemukan.

\section{Kesimpulan}

Makroalga yang ditemukan 17 spesies yang terdiri atas kelas Chlorophyta berjumlah 7 jenis, kelas Phaeophyta 3 jenis dan kelas Rhodophyta 7 jenis. Komposisi jenis kelas Chlorophyta sebesar 39\%, kelas Phaeophyta dan Rhodophyta masingmasing sebesar $37 \%$ dan $24 \%$. Indeks keseragaman makroalga sekitar 2.058 dikategorikan sedang, indeks keseragaman sekitar 0.726 dikategorikan tinggi dan indeks dominansi 0.198 dikategorikan rendah.

\section{Daftar Pustaka}

Ayhuan, HV., NP. Zamani., D. Soedharma. 2017. Analisis Struktur Komunitas Makroalga Ekonomis Penting Di Perairan Intertidal Manokwari, Papua Barat. Jurnal Teknologi Perikanan dan Kelautan Vol. 8 No. 1 Mei: 19-38.

Atmadja, WS., A. Kadi.,Sulistijo., Rachmaniar. 1996. Pengenalan jenis-jenis rumput laut di Indonesia.Pusat Penelitian dan Pengembangan Oseanologi-LIPI, Jakarta.

Boo, SM., KM. Lee, GY. Cho dan W. Nelson. 2011. Colpomenia claytonii sp . nov. (Scytosiphonaceae, Phaeophyceae) based on morphology and mitochondrial cox 3 sequences. Bot. Mar. 54 :159 - 167.

Brower, JE., JH Zar dan C.von Ende. 1998. Ekologi Umum. Metode Lapangan dan Laboratorium.
Wm,C.Brown Company Publisher, Dubuque, Lowa.

Dawes, CJ. 1998. Marine Botany. Second Edition. John Wiley and Sons, Inc. University of South Florida.

Duxbury, AC dan AB. Fuxbury. 1989. Oceans and introduction to the world.Wm. C. Publisher, USA.

English, S., Wilkinson, C., Baker, V. 1997. Survey manual for Tropical Marine Resources, $2^{\text {nd }}$ Edition. Townsville: Australian Institute of Marine Science.

Hutagalung, HP. 1988. Pengaruh Suhu Terhadap Kehidupan Organisme Laut. Pewarta Oseana. LON-LIPI: Jakarta.

Indriani, H dan E. Sumiarsih, 1992. Budidaya, Pengolahan, dan Pemasaran Rumput Laut. Penerbit Penabur swadaya, Jakarta.

Juneidi, W. 2004. Rumput laut, jenis dan Morfologinya. Jakarta. Departemen Pendidikan nasional.

Kilinç B, Cirik S, Turan G. 2013. Seaweeds for food and industrial applications. Food Industry. In: Muzzalupo I (ed). InTech. Doi.

Kadi A. 1988. Rumput Laut (Alga), Jenis, Reproduksi, Produksi, Budidaya dan Pasca Panen. Jakarta: Lipi.

Kadi, dan Atmajaya, W. S., 1988. Rumput Laut (Alga), Jenis, Reproduksi, Produksi, Budidaya dan Pasca Panen. LIPI. Jakarta.

Luning, K. 1990. Seaweeds: Their Environment, Biogeography and Ecophysiology. John Wiley and Sons, Inc.

Manoa, 2001. Marine Algae. Acanthophora spicifera. Hawai'i: Botany Departmen. University of Hawai'i.

Mishra VK, Temelli F, Shacklock PFO. 1993. Lipids of the red alga Palmaria palmata. Bot Mar 36 (2): 169-174.

McNaughton, S.J., Wolf, L. 1990. Ekologi Umum. UGM Press. Yogyakarta. 
Nirwan, A. Aidah A.A. Husain, Muh. Farid Samawi. 2013. Struktur Komunitas alga koralin bentuk percabangan Pada kondisi perairan yang berbeda di pulau Laelae, Bonebatang dan Badi : Jurusan Ilmu Kelautan Universitas Hasanuddin: Makassar.

Nybakken.1992. Biologi Laut Suatu Pendekatan Ekologis. Jakarta : Gramedia Pustaka Utama.

Odum, E. P.1993. Dasar-Dasar Ekologi. Terjemahan Samigan dan B. Srigadi. Gaja Mada Univ. Press. Jogjakarta.

Palallo, A. 2013. Distribusi Makroalga pada Ekosistem Lamun dan Terumbu Karang di Pulau
Bonebatang, Kecamatan Ujung

Tanah, Kelurahan lompo, Makassar. Skripsi FKIP.UNHAS.

Tomascik, T., A.J. Mah, A. Nontji, and M.K. Moosa. 1997. The Ecology of the Indonesian Seas. Part Two. Singapore. Periplus.

Widyastuti, S., 2008. Pengolahan Pasca

Panen Alga Merah Strain Lokal Lombok Menjadi Agar-agar Menggunakan Dua Metode Ekstraksi. Jurnal Penelitian Unram (2)14: 63-7.

www. algaebase. org. Database of Information on Alga That Includes Terrestrial, Marine and Freswater Organism. Diakses bulan Januari 2015. 